\title{
Student Expectations Regarding Online Learning: Implications For Distance Learning Programs
}

Duncan G. LaBay, (E-mail: Duncan_laBay@uml.edu), University of Massachusetts, Lowell Clare L. Comm, (E-mail: clare_comm@uml.edu), University of Massachusetts, Lowell

\begin{abstract}
What are student expectations in a traditional course versus a distance learning course? The authors analyze student course selection and expected outcomes from data collected in an undergraduate marketing course at a public university in the Northeast. Key findings reveal that students generally have a favorable predisposition towards online coursework despite their beliefs that online courses require more work and have lower learning outcomes. Further, this case study provides an initial step in better understanding student expectations in online courses as well as in the traditional classroom.
\end{abstract}

\section{Introduction}

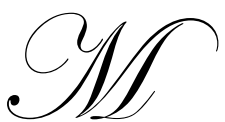

uch research has been conducted on what professors' expectations are for students taking courses and students' satisfaction at the completion of courses (Comm and Mathaisel 2002). However, little research has been done on what students expect when taking courses, especially distance learning courses. This case study is part of an ongoing research effort in understanding student buyer behavior and outcomes in a public university's online education program that is one of the largest providers of online education in New England.

\section{Background}

\section{Research on Distance Learning}

Distance learning is experiencing major growth in the United States. According to the International Data Corporation (2002), 85\% of U.S. colleges offered distance education courses to over 2 million students. This was four times the enrollment of 1998. Almost half of all schools in the public sector offer an online degree compared to slightly more than one-fifth in the private sector (Allen and Seaman 2003). Currently, it is a rare college that does not offer some form of online study. There are many reasons for this trend, the most obvious being that there is a great demand for this type of education, due to the increasing number of older adult learners with varying lifestyles in the populations. In order to remain competitive, colleges must offer this type of learning. Further, when higher education costs and teacher shortages are an issue, distance learning makes sense.

The great advantage of distance learning is convenience for the student and faculty member. Students and faculty are constrained only by the need for an internet server. Some faculty maintain that students are more thoughtful with their comments in a distance learning environment when their comments are written in the form of a memo, versus spoken with little thought as to their structure.

Although the future for distance learning is promising, there are some concerns. Is the quality of distance learning as good, better, or worse than in the traditional classroom? Is distance learning cost effective for the school 
and the student? Does distance learning foster an environment for easier student cheating? The answers to these questions may well dictate the future of distance learning.

\section{Research on Buyer Behavior}

Expectations are defined as "a level of service which the customer hopes to receive" (Zeithaml and Bitner 2002). In higher education, students expect a high level, not just an adequate level, of satisfaction. In traditional courses, students have tended to focus on specific behaviors and aspects of teaching and grading, including whether the grading policy is clearly stated on the syllabus or early in the term, whether guest lectures and outside speakers are used, and what audiovisual materials are incorporated in the course.

For distance learning, most research has focused on the expectations for potential online students. Uhlig (2002) found that the online student is expected to:

- $\quad$ Participate in the virtual classroom 7 days a week

- $\quad$ Be able to work with others in completing projects

- $\quad$ Be able to use technology properly

- $\quad$ Be able to meet the minimum standards set forth by the institution

- $\quad$ Be able to complete assignments on time

- $\quad$ Enjoy expressing higher ideas in writing

Ironically, most of the efforts in distance learning try to recreate online that which fosters learning in the traditional classroom (Beck 2002). The reason is because many people believe that high quality learning cannot take place outside of a traditional classroom environment (Uhlig 2002). If a traditional environment is the student's expectation, then he/she is not a good candidate for on-line learning. Even with chat rooms in the virtual classroom, the interactive learning experience is not the same as being with other students in a classroom.

Drawing an analogy to the traditional classroom regarding the success of distance education courses, Tricker et al (2001) reported on research of the students' perceptions. Their students evaluated distance education courses using customer satisfaction techniques that would be similar for all service industries.

Beard and Harper (2002) compared student attitudes and opinions toward in-class and online course instruction. Many of the students in their study had never taken an Internet based course. Some students expressed concern about the lack of instructor interaction (as did the instructor) and the inability to interact with other students. There were also hardware and software concerns in terms of some students trying to connect to the website. All students stated that they would take another Internet course, even though some said that while they would take another Internet course, they preferred interaction with the instructor.

Allen and Seaman (2003) surveyed over 3000 chief academic officers at degree granting institutions of higher education in the United States. They found that attitudes towards the quality of the courses offered online are changing, and a majority of academic officers believe the learning outcomes for online courses will equal or exceed that of face-to-face courses within three years. These same academic leaders perceive that attitudes of faculty at their schools remain more conservative with regard to the quality of online education and its ability to equal face-to-face learning.

LaBay and Comm (2003) looked at gap analysis to assess distance learning versus traditional course delivery. They found that traditional and online students hold similar expectations concerning course outcomes, regardless of the delivery method of the course. Their research focused on the students' evaluations of the instructor with the expectations that the instructor will be knowledgeable, well prepared, organized, offer clear and understandable explanations, encourage and properly respond to student questions, be fair and timely in graded evaluations, and in general run an effective course. 


\section{Method}

A self-administered written survey instrument was developed and administered to all students enrolled in a traditional (in-class) undergraduate Principles of Marketing course at a major state-funded university in the Northeastern United States. The course is a required core course in the curriculum for all business majors at the college. Primarily enrolled by juniors, the course also includes a smaller number of sophomores and some seniors.

The questionnaire was administered on the first day of the term and generated a sample size of 116 completed surveys. Based on the course chosen for the data collection, the survey provided a representative crosssection sample of all 1200 day-program undergraduate business majors at the college. In addition to providing traditional classes, the university is also a major provider of online education. A significant number of undergraduate and graduate business courses, including the Principles of Marketing course, are available to students online, although most day students tend to opt for the in-class courses.

The survey captured the following general information:

- $\quad$ Factors of importance in the choice of courses

- Factors of importance in the content and other aspects of class administration

- $\quad$ Prior and current online course experience

- $\quad$ Attitudes and beliefs regarding online versus traditional courses

- Demographic profile of the respondents

Factors of Importance in the Choice of Courses

The survey asked respondents to indicate the importance of each of a series of factors when they decide which courses to take each term. A five-point response scale was used, from "very important" to "not at all important". The following factors were considered:

$$
\begin{array}{ll}
- & \text { Course content } \\
\text { - } & \text { Reputation of the instructor } \\
\text { - } & \text { Fits my work schedule } \\
\text { - } & \text { Convenient time of day } \\
\text { - } & \text { Convenient day(s) of week }
\end{array}
$$

\section{Factors of Importance in the Content and Aspects of Class Administration}

Respondents were asked to rate the importance of each of a series of class aspects in terms of the content and administration of courses. Using the same five-point response scale as previously described, students rated the importance of the following class aspects:
- Organizational content of course lectures
- $\quad$ Visual materials used during class
- $\quad$ Handouts for note taking
- Class participation by others in the class
- $\quad$ Class participation by yourself in the class
- Individual exercises used in class
- $\quad$ Student class participation
- $\quad$ Semester project
- $\quad$ Working with team members 


\section{Prior and Current Online Course Experience}

Respondents were asked whether they had previously taken any online courses through the University, and whether they were currently enrolled in University online coursework.

Attitudes and Beliefs Regarding Online versus Traditional Courses

Respondents were asked attitudinal questions regarding online versus traditional course delivery, including:

- Expectations regarding perceived differences in online course workload requirements, educational outcomes, grading, and course pricing

- $\quad$ Perceived advantages and disadvantages of online delivery

- Interest in enrolling for online courses, given a choice of delivery method

\section{Demographic Profile of Respondents}

Demographic measures that were collected included the student's major, class standing, credit hours enrolled in the current term, employment status in the current term, housing status, and age.

\section{Findings}

The majority of the students surveyed were not among those who had experience with the university's online courses. Of 116 survey respondents, 110 had never taken a university online course. Of the six who had, five reported having taken one online course, one had taken two online courses, and one of these students was currently enrolled in a single online course. Based on the extremely small incidence of actual online course experience (5\%), these respondents present an interesting perspective on online course expectations.

\section{Course Choice Decision Factors}

As shown in Table 1, respondents ranked course content (2.10 mean rating on a scale of 1 to 5 , where 1 is most important) and reputation of instructor (2.24) as the two most important factors in deciding which courses to take each term. Convenience, both in terms of time of day (2.48) and day(s) of week (2.67), was of somewhat less importance to the students. Having classes that fit either a work (2.94) or social/sleep schedule (3.09) were ranked lowest among the six factors considered, despite the commonly-held perception among some faculty to the contrary.

Cross tabulations were carried out on each of these factors, comparing those who expressed an interest in taking online courses with those who were not interested in online courses. Interestingly, the respondent ratings of course choice factors showed remarkable consistency, irrespective of the level of interest in online courses. No statistically significant differences were found in these cross tabulations (Table 1).

\section{Aspects of Class Pedagogy}

Among various aspects of class pedagogy and administration, respondents ranked organization and content of lectures (1.93 mean rating), having handouts for note taking (2.01), and the presence of visual materials during class (2.13) to be of highest importance to them (see Table 2).

A second tier of factors includes the use of individual exercises in class (2.56), working with team members (2.68), and class participation, both individual (2.78) and by others (2.99). Lowest in the ranking were the incorporation of semester projects (3.20) and student class presentations (3.45).

Cross tabulations of these ratings by level of interest in online courses showed remarkably similar results, irrespective of whether the student was positively or negatively inclined towards enrolling in online courses. Once again, no significant differences were found in these cross tabulations (Table 2). 


\section{Attitudes and Beliefs Concerning Online Courses}

Respondents perceive significant differences between online and traditional classes with regard to workload, educational outcomes, and appropriate pricing. Expectations concerning grading are largely similar between the two delivery methods.

As shown in Table 3, respondents believe that online courses present the student with a greater workload, compared with taking the same class face-to-face. They also believe that students learn less about the subject as a result of taking an online course. Taken together, these two findings could explain a third finding, that respondents believe the online courses should be priced lower than traditional classes.

Students believe there is one overwhelming advantage to online courses - convenience. This advantage is expressed by $90 \%$ of respondents and is expressed as a general convenience, a location convenience, and a time convenience (Table 4).

Conversely, the two primary disadvantages of online courses that are mentioned by respondents are the lack of face-to-face contact and the absence of a classroom setting (Table 4).

Despite these attitudes and beliefs, students remain potentially interested in online classes. Two-thirds of all respondents were somewhat or extremely interested in taking an online section, if both options were available (54\% were somewhat interested, and $13 \%$ reported being extremely interested). Only one-third were negatively predisposed, including $20 \%$ who were not very interested and $13 \%$ who were not at all interested in an online option.

\section{Demographic Profile of Respondents}

Table 5 provides a demographic profile of the survey respondents. As expected, these students were largely business majors (87\%) in their sophomore or junior year (88\%) and ranging in age between 19-22 (83\%).

The majority of respondents (60\%) were carrying a 15-17 credit-hour load of courses, with $19 \%$ taking 18 credits or more. In keeping with the profile of the students at the University, a sizeable percentage of respondents were working at least half time (48\%), and the majority were not living on campus (72\%). Taken together, the responses to these three measures suggest a population of students who have extremely full and busy schedules.

\section{Discussion and Implications}

This study reveals a number of significant issues for educators involved in the design and delivery of online coursework. Specifically,

- $\quad$ Students believe online courses require more work, have lower learning outcomes, and should be priced lower than traditional courses.

- Despite these beliefs, students generally have a favorable predisposition towards online coursework as an alternative to traditional course delivery methods

- $\quad$ Convenience is the key selling feature for online courses.

- $\quad$ Online courses must develop features and methods of delivery that address the perceived disadvantage of no face-to-face contact with other students and the instructor.

- $\quad$ Student ratings of [1] factors of importance in course decisions and [2] factors of importance regarding content and other aspects of administration are remarkably consistent, irrespective of the student's level of interest in online education.

Overall, when choosing either traditional or online courses, students have similar factors of importance in mind. This could be because of no experience with distance learning, so they resort to their old methods of course selection, whether they are appropriate or not for online education. 
Students at this university do generally have a favorable predisposition towards online courses despite their perceived problems with online courses. The question is - are these perceived problems, such as the requirement of more work in online courses, lower learning outcomes and higher prices, actually realistic at most universities? If these problems are realistic then it appears that students are favorably predisposed to distance education, because of the other mentioned factors of convenience and easier grading policies.

\section{Marketing Techniques for Online Education}

Based on the research findings of this study, a number of possible marketing strategic initiatives should be considered by online education administrators, including:

- $\quad$ Target market - traditional college students and older adults with work or childcare obligations

- $\quad$ Product - online education

- $\quad$ Place - via the internet

- $\quad$ Price - same as traditional courses, not higher prices

- $\quad$ Promotion - advertising, personal selling, publicity and public relations, direct marketing

Promotion becomes particularly important to distance learning programs in terms of stressing their convenience and overcoming the lack of face-to-face contact with other students and the instructor. The tools which can be used are advertising, sales promotion, public relations and publicity, personal selling, and direct marketing. In brochures, newspaper and television advertising, on their websites, and in personal recruiting, colleges can stress the convenience (minimizing time, money, and effort) of taking online courses.

Similarly, lack of face-to-face contact can be overcome by stressing the significance of chat rooms and the opportunity for students to visit professors during office hours on campus if they desire. In fact, some distance learning courses actually do administer exams on campus. What the university must do is attempt to make an intangible product (distance learning) become more tangible to the consumer (student). In addition, the distance learning courses must be inseparable. In other words, promote the reputation of the traditional university along with its distance learning programs. Obviously, both programs should be consistent with the stated mission of the institution.

All promotional materials for distance learning programs must clearly articulate the overall benefits that students will derive in terms of learning effectiveness. The key factor to be stressed must be the educational outcome or learning for the student.

\section{Future Issues}

Over time, as students become more familiar with, and participate in, a greater number of online courses, and those using a hybrid delivery method, one would anticipate a greater congruence between student expectations and learning outcomes. Future research in the area of outcome assessment will document whether online initiatives are successful in achieving a merging of these expectations with appropriate academic outcomes. 
Table 1 Factors of Importance in Course Choice Decisions

Question: When you decide which courses to take each semester, how important are each of the following factors?

[Scale: $1=$ very important, $5=$ not at all important]

\section{$\underline{\text { All Respondents }}$}

Course content

Reputation of instructor

Convenient time of day

Convenient day(s) of week

Fits my work schedule

Fits my social/sleep schedule

$\begin{array}{lll}\mathbf{1} & \mathbf{2} & \mathbf{3} \\ 31 \% & 37 & 26 \\ 36 & 26 & 22 \\ 23 & 30 & 30 \\ 19 & 24 & 38 \\ 25 & 21 & 15 \\ 13 & 16 & 37\end{array}$

\section{4}

5

Mean

$\begin{array}{lll}3 & 3 & 2.10\end{array}$

$\begin{array}{lll}10 & 6 & 2.24\end{array}$

$\begin{array}{lll}10 & 7 & 2.48\end{array}$

$\begin{array}{lll}9 & 10 & 2.67\end{array}$

$\begin{array}{lll}13 & 26 & 2.94\end{array}$

$\begin{array}{lll}17 & 17 & 3.09\end{array}$

\section{Mean Ratings of Factors by Online Course Interest}

Interest in online course?

Course content

Reputation of instructor

Convenient time of day

Convenient day(s) of week

Fits my work schedule

Fits my social/sleep schedule

\section{Positive}

2.16

2.33

2.45

.53

2.96

.10
Negative

2.10

2.13

2.56

2.90

2.95

3.08
Significance*

NS

NS

NS

NS

NS

NS

$* \mathrm{NS}=$ difference in mean ratings of factor across online interest is not significant at the .05 -level 
Table 2 Importance of Aspects of Class Pedagogy

Question: How important to you are each of the following aspects of classes here at the University?

[Scale: $1=$ very important, $5=$ not at all important]

\section{All Respondents}

Organization/content of lectures

Handouts for note taking

Visual materials during class

Individual exercises in class

Working with team members

Class participation - self

Class participation - others

Semester project

Student class presentations

$\begin{array}{lccccc}\mathbf{1} & \mathbf{2} & \mathbf{3} & \mathbf{4} & \mathbf{5} & \text { Mean } \\ 39 \% & 33 & 25 & 2 & 1 & 1.93 \\ 37 & 36 & 17 & 9 & 1 & 2.01 \\ 29 & 39 & 23 & 8 & 1 & 2.13 \\ 13 & 37 & 32 & 17 & 1 & 2.56 \\ 20 & 25 & 31 & 15 & 9 & 2.68 \\ 16 & 26 & 32 & 16 & 10 & 2.78 \\ 9 & 23 & 37 & 22 & 9 & 2.99 \\ 8 & 16 & 37 & 26 & 13 & 3.20 \\ 7 & 16 & 28 & 23 & 26 & 3.45\end{array}$

$\underline{\text { Mean Ratings of Factors by Online Course Interest }}$

$\begin{array}{llll}\text { Interest in online course? } & \text { Positive } & \text { Negative } & \text { Significance* } \\ \text { Organization/content of lectures } & 1.95 & 1.87 & \text { NS } \\ \text { Handouts for note taking } & 2.00 & 2.02 & \text { NS } \\ \text { Visual materials during class } & 2.17 & 2.40 & \text { NS } \\ \text { Individual exercises in class } & 2.65 & 2.33 & \text { NS } \\ \text { Working with team members } & 2.67 & 2.72 & \text { NS } \\ \text { Class participation - self } & 2.89 & 2.58 & \text { NS } \\ \text { Class participation - others } & 3.03 & 2.97 & \text { NS } \\ \text { Semester project } & 3.25 & 3.15 & \text { NS } \\ \text { Student class presentations } & 3.76 & 3.38 & \text { NS }\end{array}$

$* \mathrm{NS}=$ difference in mean ratings of factor across online interest is not significant at the .05 -level 
Table 3 Expectations Concerning Workload, Educational Outcome, Grading, and Pricing of Online Courses

\section{Workload, Educational Outcome, and Grading Questions}

Question: For a typical course, how much difference do you think there is in traditional in-class course delivery?

\section{Workload}

1 the online course workload is significantly greater

2 the online workload is somewhat greater

3 the workload for the online and traditional course are about the same

4 the online workload is somewhat less

5 the online workload is significantly less

\section{Educational Outcome (how much the student learns about the subject)}

1 the online student learns significantly more

2 the online student learns somewhat more

3 the student learning is about the same in either course

4 the online student learns somewhat less

5 the online student learns significantly less

\section{Grading}

1 it is significantly easier to get a good grade in an online course

2 it is somewhat easier to get a good grade in an online course

3 grading in an online and traditional course is about the same

4 it is somewhat easier to get a good grade in a traditional course

5 it is significantly easier to get a good grade in a traditional course

\section{Pricing Question}

Question: How do you think the University should price an online course, compared to a traditional course?

1 the online course should be priced significantly higher

2 the online course should be priced somewhat higher

3 the online and traditional course should be priced the same

4 the online course should be priced somewhat lower

5 the online course should be priced significantly lower

Table 3, continued

\section{Findings}

\begin{tabular}{lccccccc}
\hline & $\mathbf{1}$ & $\mathbf{2}$ & $\mathbf{3}$ & $\mathbf{4}$ & $\mathbf{5}$ & Mean & Significance* \\
$\begin{array}{l}\text { Workload } \\
{[1=\text { greater online }]}\end{array}$ & $6 \%$ & 31 & 44 & 17 & 2 & 2.78 & .01 \\
$\begin{array}{l}\text { Educational outcome } \\
{[1=\text { learn more online }]}\end{array}$ & 2 & 6 & 41 & 44 & 7 & 3.48 & .01 \\
$\begin{array}{l}\text { Grading } \\
{[1=\text { easier online }]}\end{array}$ & 3 & 29 & 46 & 18 & 4 & 2.91 & NS \\
$\begin{array}{l}\text { Pricing } \\
{[1=\text { higher online }]}\end{array}$ & 3 & 4 & 39 & 38 & 16 & 3.60 & .01
\end{tabular}

* Level of statistical significance shown, comparing mean rating with expected value under the null hypothesis. (NS = no significant difference.) 
Table 4 Perceived Advantages and Disadvantages of Online Courses

Question: Comparing online and traditional courses, what would you say are the greatest advantages to taking a course online? (Open-ended)

Convenience - time $\quad 37 \%$

Convenience - location $\quad 22 \%$

Convenience - general $21 \%$

Get more out of it $\quad 2 \%$

Other $\quad 18 \%$

Question: and the greatest disadvantages to the online courses? (Open-ended)

No face-to-face $\quad 63 \%$

No classroom $14 \%$

Learn less $\quad 5 \%$

Cost $2 \%$

No computer access $\quad 2 \%$

Other $14 \%$

Table 5 Demographic Profile of Respondents

Major

Business

Other majors

8

Undeclared

Class Standing

Freshman $\quad 8 \%$

Sophomore $\quad 48 \%$

Junior $\quad 40 \%$

Senior $\quad 4 \%$

Credit Hours this Semester

Less than 12

18 credits or more $\quad 19 \%$

Employment Status this Semester

40 hours or more $\quad 4 \%$

$20-39$ hours $\quad 44 \%$

$10-19$ hours $\quad 35 \%$

Less than 10 hours $\quad 5 \%$

Not working $12 \%$

Housing

On-campus $\quad 28 \%$

Off-campus, within 15 miles $\quad 47 \%$

Off-campus, beyond 15 miles $\quad 25 \%$

Age

19 - 20 years old $\quad 42 \%$

$21-22 \quad 41 \%$

$23-25 \quad 8 \%$

Over $25 \quad 9 \%$ 


\section{References}

1. Allen, E. and J. Seaman. 2003. Sizing the opportunity: the quality and extent of online education in the U.S., 2003 and 2003. The Sloan Consortium.

2. Beard, L. and C. Harper. 2002. Student perceptions of online versus on campus instruction. Education 122 (4): 658-663.

3. Beck, E. 2002. The mysterious territory of distance learning. The NEA Higher Education Journal: Thought and Action (XVIII): 77-89.

4. Comm, C. and D. Mathaisel. 2002. Employing gap analysis from the SERVQUAL model to measure classroom outcomes. Journal of the Academy of Business Education. Volume 3, fall.

5. International Data Corporation. 2002. Online distance learning in higher education, 1998-2002. Cited in T. J. Kriger, A Virtual Revolution: Trends in the Expansion of Distance Learning. American Federation of Teachers Report. May 2001.

6. LaBay, D. and C. Comm. 2003. A case study using gap analysis to assess distance learning versus traditional course delivery. The International Journal of Educational Management 17 (7): 312-317.

7. Tricker, T., M. Rangecroft, P. Long, and P. Gilroy. 2001. Evaluating distance education courses: the student perception. Assessment and Evaluation in Higher Education 26 (2): 165.

8. Uhlig, G. 2002. The present and future of distance learning. Education 122 (4): 670-674.

9. Zeithaml, V. and M. Bitner. 2002. Services Marketing. Irwin/McGraw-Hill Publishing.

Notes 
Notes 